\title{
A SINGLE, MULTIPLEX PCR FOR DIFFERENTIATING ALL SPECIES OF TRICHINELLA
}

\author{
ZARLENGA D.S.*, CHUTE M.B.*, MARTIN A.* \& KAPEL C.M.O.*
}

\begin{abstract}
Summary :
The genus Trichinella is currently divided into seven species and at least three additional, unclassified genotypes, Trichinella T6, T8 and T9, where both T8 and TQ have been deemed very similar to T. britovi. Other than for the non-encapsulated species, the absence of distinguishing morphological characters and the overlapping nature of the biological characters within this genus make these traits unsuitable for diagnosis. Consequently, we have developed a simple PCR test for the unequivocal differentiation of all currently recognized species of Trichinella including Trichinella T6. DNA sequence data from each Trichinella genotype were generated from internal transcribed spacers, ITS1 and ITS2, and from expansion segment $V$ (ESV) of the rDNA repeat, from which five different PCR primer sets were chosen. When used simultaneously, this primer mix generates a simple and unique electrophoretic DNA banding pattern for each species and genotype. The ESV-derived primer set contributes at least one band to each agarose gel-derived genotypic pattern and therefore functions as an internal control for PCR integrity. Geographical isolates of each Trichinella genotype were used to verify the reliability and reproducibility of respective DNA banding patterns using single muscle larvae.
\end{abstract}

KEY WORDS : diagnosis, PCR, multiplex, ribosomal DNA.

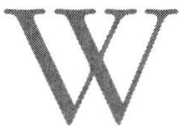
ithin most parasite genera, distinct morphological and/or biological characters exist among the species that permit differentiation and classification. However, other than for non-encapsulated species, the absence of distinguishing morphological characters and the overlapping nature of the biological characters within the genus Trichinella make these traits unsuitable for accurate diagnosis.

In 1988 the International Commission on Trichinellosis established the Trichinella Reference Center (TRC) (Pozio et al., 1989) at the Istituto Superiore di Sanita' in Rome, Italy, and empowered it to function as an international resource for identifying and cryopreserving Trichinella parasites. Since that time, and for

\footnotetext{
* U.S. Department of Agriculture, ARS, Immunology and Disease Resistance Lab, Beltsville MD, 20705 USA.

zarlenga@lpsi.barc.usda.gov
}

some years prior, the methods used by the TRC for Trichinella differentiation have been based primarily on biochemical and molecular characters, though multifaceted approaches have been invoked for isolates of greater interest.

Currently, the most reliable methods for Trichinella differentiation are based upon PCR for its ease of use, sensitivity and objectivity in differentiating genotypes. Numerous researchers have utilized both random amplified polymorphic DNA (RAPD) primers (Arribas et al., 1994; Bandi et al., 1993; Dupouy-Camet et al., 1994) as well as specific primers (Wu et al., 1997; Wu et al., 1998) to achieve this goal. The major drawback of RAPD-derived techniques has been the lack of specificity and reproducibility whereby a complete bank of positive controls must be run with each analysis. The use of species/genotype specific primers, though preferable, can require a substantial amount of trial and error for proper identification. Some have tried to minimize these problems by secondary treatment of PCR products with restriction enzymes (PCR-RFLP) for final differentiation (Wu et al., 1999); however, since multiple steps are required, this potentially can lead to incorrect diagnosis should extraneous factors effect subsequent reactions and data interpretation. Zarlenga et al. (1999) recently developed a multiplex PCR test based upon sequence length polymorphism within the ESV region and sequence variability within the ITS that simplifies Trichinella differentiation into a single step PCR. Herein we summarize the development of this test and demonstrate its applicability in diagnosing the newly characterized T. papuae.

\section{MATERIALS AND METHODS}

T richinella genotypes were maintained by serial passage in Swiss-Webster female mice. Infective larvae were recovered from ground muscle tissue by pepsin- $\mathrm{HCl}$ digestion from which genomic DNA was extracted using proteinase K:SDS digestion (Zarlenga et al., 1999). 


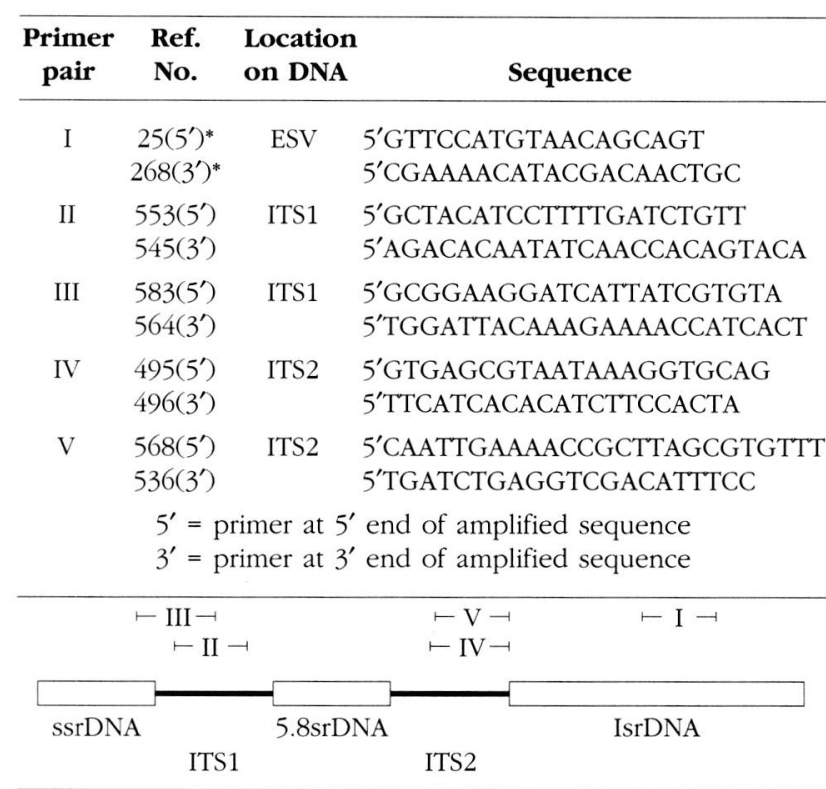

Table I. - Primer sequences for multiplex PCR.

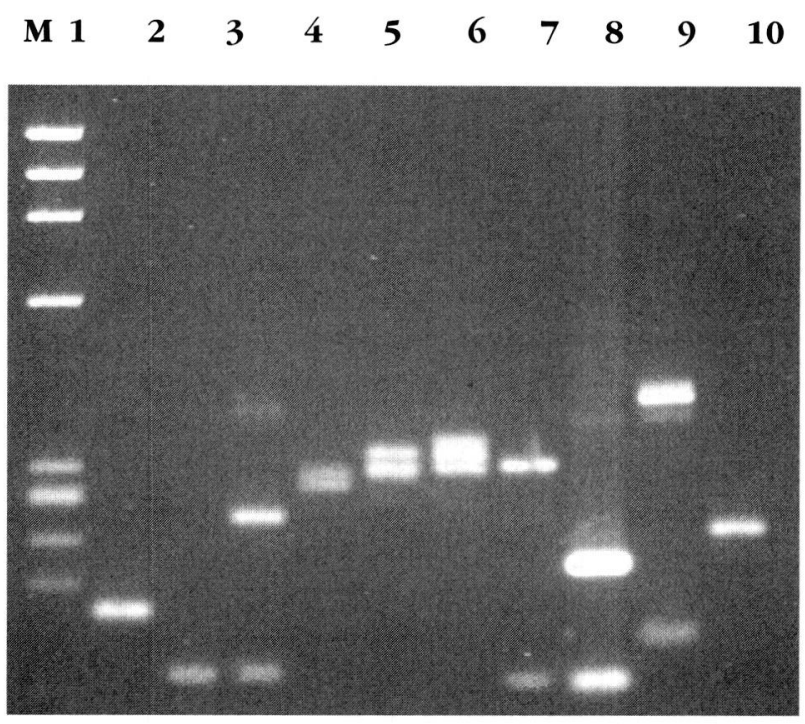

Fig. 1. - Agarose gel analysis of Trichinella multiplex PCR. Polymerase chain reaction was performed on reference strains of Trichinella and the PCR products were separated on a $2.5 \%$ Metaphor agarose gel followed by ethidium bromide staining. 1) T. spiralis 2) T. nativa; 3) T. britovi; 4) T. pseudospiralis (Russia); 5) T. pseudospiralis (USA); 6) T. pseudospiralis (Tasmania); 7) T. murrelli; 8) Trichinella T6; 9) T. nelsoni; 10) T. papuae.

\section{RESULTS}

was amplified in a multiplex PCR reaction containing primer pairs I, II, III, IV and V (Table I). Primer sets were generated from sequence alignments of both the ESV and ITS regions of the rDNA repeat from each Trichinella genotype. All primer concentrations were $0.25 \mathrm{M}$ except for primer pair IV (Table I) which was used at $0.5 \mathrm{M}$. Reactions were performed in $50 \mu \mathrm{l}$ of $\mathrm{Ex}$ Taq PCR buffer supplemented with $0.2 \mathrm{mM}$ each dNTP, 2.5 U Ex-Taq DNA polymerase (Panvera Corporation) and $1 \% \mathrm{v} / \mathrm{v}$ dimethyl sulfoxide. All reactions were carried out in a Perkin-Elmer 480 Thermal Cycler under the following cycling conditions: $94^{\circ} \mathrm{C}, 1 \mathrm{~min} ; 60^{\circ} \mathrm{C}$ $1 \mathrm{~min} ; 72^{\circ} \mathrm{C}, 2 \mathrm{~min}$, for 40 cycles. Reaction products $(5 \mu \mathrm{l})$ were separated on a $2.5 \%$ Metaphor agarose gel and detected by ethidium bromide staining.
$\mathrm{R}$ esults from agarose gel electrophoresis of multiplex PCR products using genomic DNA from reference strains of the different genotypes of Trichinella are shown in Fig. 1. The approximate size of each PCR fragment and the corresponding primer set(s) responsible for generating each fragment are summarized in Table II. Results indicate a unique and simple banding pattern for each genotype including the newly described T. papuae. At least one PCR fragment from each genotypic banding pattern was generated from the lsrDNA- derived ESV. Banding profiles were consistent among geographical isolates of similar genotype (data not shown).

\begin{tabular}{|c|c|c|c|c|c|c|c|c|c|c|c|}
\hline Primers $^{a}$ & Locus $^{b}$ & & & Tri & la ge & and $I$ & ragme & & & & \\
\hline & & $\underline{\mathrm{T} 1}$ & $\underline{\mathrm{T} 2}$ & T3 & ${\underline{\mathrm{T}} 4 \mathrm{r}^{\mathrm{d}}}^{\mathrm{d}}$ & $\underline{\mathrm{T} 4 \mathrm{t}^{\mathrm{d}}}$ & $\underline{\mathrm{T}} 4 \mathrm{u}^{\mathrm{d}}$ & $\underline{\mathrm{T} 5}$ & $\underline{\mathrm{T} 6}$ & $\underline{\mathrm{T} 7}$ & $\underline{\mathrm{T} 10}$ \\
\hline I & ESV & 173 & 127 & 127 & $310^{e}$ & $340^{e}$ & $360^{e}$ & 127 & 127 & 155 & 248 \\
\hline II & ITS1 & & & 253 & & & & & & & \\
\hline III & ITS1 & & & & & & & 210 & & & \\
\hline IV & ITS2 & & & & & & 316 & & & & \\
\hline $\mathrm{V}$ & ITS2 & & & & & & & & 404 & & \\
\hline
\end{tabular}

\footnotetext{
${ }^{a}$ Primer sets as reported in Table I.

${ }^{\mathrm{b}}$ Locus on genome where primers anneal; ESV = expansion segment V; ITS = internal transcribed spacer.

${ }^{\mathrm{c}}$ All sizes are approximate and are given in base pairs.

${ }^{\mathrm{d}} \mathrm{T} 4$ isolates from Russian ( $\mathrm{r}$ ), Tasmania (t) and the USA (u).

e Size listed involves a cluster of 2 or more fragments.

$\mathrm{T} 1=T$. SPIRALIS $; \mathrm{T} 2=$ T. NATIVA; $\mathrm{T} 3=T$. BRITOVI; T4 $=$ T. PSEUDOSPIRALIS $; \mathrm{T} 5=T$. MURRELLI $; \mathrm{T} 7=T$. NELSONI; T10 $=$ T. PAPUAE.
}

Table II. - DNA fragment sizes generated from multiplex PCR. 


\section{DISCUSSION}

$\mathrm{U}$ ntil now, a simple, one-step assay for the unilateral differentiation of all Trichinella genotypes has not been available. The multiplex PCR described herein exploits the size variability within the ESV to differentiate T. spiralis, T. pseudospiralis, T. papuae and T. nelsoni species from all other sylvatic species and genotypes. Because the ESV-derived primer set is conserved among all Trichinella genotypes studied thus far, its PCR products represent diagnostic characters as well as internal positive controls for the PCR.

Partial analysis and alignment of the ITS1 and ITS2 sequences has provided the basis upon which additional PCR primers were developed for distinguishing T. britovi and T. murrelli. A third primer set differentiates $T$. nativa from Trichinella $\mathrm{T} 6$, which is also freeze resistant and genetically similar to T. nativa. In so doing, this primer set establishes the lone appearance of the $127 \mathrm{bp}$ ESV-derived fragment common to most sylvatic genotypes, as a specific diagnostic character for T. nativa.

The reliability and reproducibility of each DNA banding pattern was verified with single muscle larvae using geographical isolates of each Trichinella genotype (data not shown). PCR amplification profiles were conserved among multiple geographical isolates representing each genotype tested, as well as individual parasites within a discrete population (data not shown). The origins of the isolates analyzed were sufficiently diverse to support the claim that the banding patterns presented here will persist as reference profiles for each genotype; however, final validation of the technique prior to routine application will require analysis of more isolates and standardization. To this end, the International Trichinella Reference Center has taken a leadership role in further validating the PCR assay and to date has successfully identified 92 isolates of T. spiralis; 84 isolates of $T$. nativa; 95 isolates of $T$. britovi; 10 isolates of $T$. pseudospiralis; 12 isolates of T. murrelli; 11 isolates of T6; 2 isolates of T. nelsoni; and 1 isolate of T. papuae.

\section{ACKNOWLEDGEMENTS}

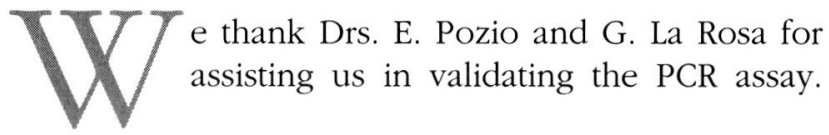

\section{REFERENCES}

Arribas B., Siles M., Bolas F. \& Martinez-Fernandez A.R. Randomly amplified DNA polymorphism within Trichinella species and isolates, in: Trichinellosis vol 8. Campbell C. W., Pozio E. \& Bruschi F. (eds), ISS Press, Rome, Italy, 1994, 55-60.

Bandi C., la Rosa G., Bardin M.G., Damiani G., de Carneri I. \& Pozıo E. Arbitrarily primed polymerase chain reaction of individual Trichinella specimens. Journal of Parasito$\log y, 1993,79,437-440$.

Dupouy-Camet J., Robert F., Gulllou J-P., Vallet C., Perret C. \& Soulé C. Genetic analysis of Trichinella isolates with random amplified polymorphic DNA markers, in: Trichinellosis, vol. 8. Campbell C. W., Pozio E. \& Brusch F. (eds), ISS Press, Rome, Italy, 1994, 83-88.

Pozio E., LA Rosa G. \& Rossi P. Trichinella Reference Center. Parasitology Today, 1989, 5, 169-170.

Wu Z., Nagano I., Fukumoto S., Saito S., Yamaguchi T., Pozio E. \& TAKaHASHI Y. Polymerase chain reaction primers to identify Trichinella spiralis or T. pseudospiralis. Parasitology International, 1997, 149-154.

Wu Z., Nagano I., Pozio E. \& Takahashi Y. Polymerase chain reaction-restriction fragment length polymorphism (PCR-RFLP) for the identification of Trichinella isolates. Parasitology, 1999, 118, 211-218.

Wu Z., Nagano I. \& Takahashi Y. The detection of Trichinella with polymerase chain reaction (PCR) primers constructed using sequences of random amplified polymorphic DNA (RAPD) or sequences of complementary DNA encoding excretory-secretory (ES) glycoproteins. Parasitology, 1998, 117, 173-183.

Zarlenga D.S., Chute M. B., Martin A. \& Kapel C. M. O. A multiplex PCR for unequivocal differentiation of six encapsulated and three non-encapsulated genotypes of Trichinella. International Journal of Parasitology, 1999, 29, 141149. 